\title{
El Lugar de Lilith en los Cuencos de Magia Judeo- Aramaicos.
}

\author{
Lilith's Place in Jewish- Aramaic Magic Bowls.
}

Jesús Galisteo L.,

g.1.jesus@hotmail.com

Doctorando de la Universidad de Cádiz

\begin{abstract}
Resumen: Entre los demonios presentes en las creencias del imaginario común próximo oriental destaca un espíritu maligno femenino, cuyas tradiciones han evolucionado y se han distorsionado hasta metamorfosearse en un icono de feminidad. El objetivo de este artículo es buscar las raíces de la creencia en este ser entre las poblaciones judías de la diáspora en la Antigüedad Tardía, a través de un fenómeno exclusivo de ese intervalo de tiempo, los cuencos de magia, así como las repercusiones sociales y soluciones extraordinarias derivadas de las consecuencias que produjo la creencia en este demonio femenino.
\end{abstract}

Palabras clave: Lilith, demonios, cuencos de magia, exorcismos, divorcios.

Abstract: Among the demons present in the beliefs of the Eastern Near common imaginary highlights a female evil spirit, whose traditions have evolutioned and they have distorted until metamorphose in a feminity icon. The objetive of this article is search for the roots of beliefs in this being among diaspora Jewish populations in Late Antiquity, through a exclusive phenomenon of that interval time, the magic bowls, as well as the social aftermath and extraordinary solutions derivatives of consequences that produced the belief in this female demon.

Keywords: Lilith, demons, magic bowls, exorcisms, divorce.

\section{Introducción.}

En este estudio se abordará la relevancia que ocupa un demonio femenino del mundo antiguo de orígenes mesopotámicos, añadido a las creencias judaicas durante el cautiverio babilónico (587537 a. C.) o quizás antes por el contacto comercial y trasvase de ideas religiosas en la franja próximo oriental y, de posterior adopción cristiana y mandea, que tuvo una gran repercusión y protagonismo en la magia tardoantigua, siendo el enemigo a combatir entre los más populares de los terrores y pesadillas de la superstición y fenomenología daimónica en las familias judaicas o cercanas a ellas, teniendo que acudir a sus rabinos o magos para pedir sus servicios como expertos en la materia por su oficio para luchar contra este demonio. 
A lo que habría que añadir la singularidad de ser el demonio, o más bien habría que hablar del conjunto de demonios, femeninos por antonomasia en la demonología judaica a examinar, pues salvando el caso protagonizado por Rabbí Hanina Ben Dosa, todo demonio o espíritu maligno o inmundo de naturaleza y sexo femenino es denominado como lilith o lili.

Aquí analizaré la presencia y construcción de Lilith que se desprende de los textos epigráficos de finalidad mágica, sanadora y exorcística. Para esta labor tomaré como fuente y referencia los cuencos de magia judeo- aramaicos, fenómeno de la religiosidad tardoantigua próximo oriental, con el fin de recuperar la imagen y creencia ancestral liliana, lejos de las contaminaciones y relecturas posteriores de este demonio transformado en arquetipo femenino o $<\langle$ feminista $\rangle\rangle^{1}$.

Para ello, en este artículo contextualizaré la religiosidad y superstición que rodea a los cuencos de magia, analizaré éstos para acercarnos al fenómeno tardoantiguo, desarrollaré cuál fue la presencia demonológica presente en los cuencos y, por supuesto, esbozaré el papel que desarrolló Lilith en la mitología y textos judaicos antiguos, profundizando en el desempeñado en las creencias más cercanas y reales, tanto elitistas como populares, presente en los cuencos de magia.

\section{La magia tardoantigua.}

Comprendida entre los siglos I a VII no solo es heredera de las temáticas y formas anteriores, sino que está en proceso de transformación, como otras áreas de la sociedad y la cultura, pero sobre todo va a la zaga de la religión de su tiempo, pues las transformaciones vividas en los diferentes cultos deja su huella en la parte heterodoxa que comprende la magia, ya que ésta no es más que un reflejo y vía de escape de la ortodoxia.

La magia tardoantigua presente en el Próximo Oriente y en la franja mediterránea se desarrolló principalmente de las tradiciones mesopotámicas y egipcias, y la visión esotérica, exótica en gran parte, que los demás estados tuvieron de ellas contribuyeron a formar los propios.

Calificada como superstición, lo cierto es que en la mayoría de los casos, teólogos, historiadores de las religiones, antropólogos y sociólogos caen en una indefinición de la misma respecto de la religión como fenómeno cultual y ritualístico. De hecho, cuando estudiamos manifestaciones religiosas como la magia, los exorcismos u otras plasmaciones de la ritualidad la imprecisión de sus temáticas y escenificaciones abre brecha en los planteamientos de los expertos, tanto internos, como en el caso de los propios religiosos y externos, como en el académico, provocando debates que basculan entre la necesidad de calificarlos como ortodoxia o heterodoxia.

Parece que en gran medida recurre a la idolatría ${ }^{2}$, otorgándole reconocimiento y poder a potencias $a$ priori rechazadas por los monoteísmos.

${ }^{1}$ Burguillos Capel. M. "Non Serviam: La Insubordinación Femenina en el Mito de Lilith", en Locas, escritoras y personajes femeninos cuestionando las normas: XII Congreso Internacional del Grupo de Investigación Escritoras y Escrituras (Ponencia) Sevilla, 2015, pp. 188- 198.

${ }^{2}$ En el caso de los cuencos de magia judeo- aramaicos encontramos tanto el empoderamiento de demonios que quizá fueron dioses orientales en otras culturas antiguas como presencia de nombres paganos relevantes y 
Para que la magia pudiera ser un vehículo de transformación de la realidad está debía valerse de hechizos, conjuros, encantamientos o ensalmos que diesen oralidad a sus deseos, pues para el ser humano, la palabra es la mejor forma de manifestar nuestra voluntad.

Pero para que ésta tuviese perpetuidad y cumplimiento se necesitaba de unos ritos, un conjunto de acciones que marcasen de forma espacio- temporal que nuestros anhelos habían tenido cumplimiento en un momento exacto y sin errores posibles, con la exactitud debida al rito como hecho modificador.

Y, por supuesto, un soporte donde la palabra quedara escrita, como forma de eternizarla ${ }^{3}$, y en ocasiones poder llevarla consigo, ocultarlas en lugares santos o exhibirlas o semi- ocultarlas en los hogares para la protección propia de los familiares y moradores de la misma ${ }^{4}$. Para ello se crearon amuletos, cuyos fines eran apotropaicos, sanadores, protectores, exorcísticos o conjuradores.

Pero también desarrollaron formas más negativas de la magia, legado de las formas punitivas, trascendentes y escatológicas destinadas a proteger las tumbas de los monarcas de la antigüedad más remota, las maldiciones.

La multitud de fórmulas presentes en los textos los define y enriquece, creando una variedad temática amplísima, aunque de modelos similares, generando así talleres de escribas cuyos oficios mágicos se iban especializando. De este modo los magos dotaron sus escritos y amuletos de simbología, voces magica, atribuciones mágicas a la repetición de letras o palabras (principalmente las vocales del alfabeto griego a las que se les asignaba un gran poder oculto, pero también el uso del tetragramatón יהוה, tanto entre comunidades judías como no judías, por la potencia inherente asignada al nombre del Dios hebreo), numerología y gematría ${ }^{5}$.

Asimismo, las artes mánticas o sortílegas, permitidas en gran parte del paganismo, fueron prohibidas por los principales monoteísmos, no solo por motivos religiosos sino también políticos tal y como nos reflejan las leyes romanas del Bajo Imperio. A veces, tomando formas y significados astrológicos. Las razones teológicas que parecen trascender de la prohibición de la adivinación por parte de los judeocristianos es que mientras que la adivinación, en sus múltiples manifestaciones, es buscada o provocada y no siempre quien responde es la divinidad, lo cual crea la posibilidad de ser engañado, el profetismo es involuntario, pues es la divinidad quien elige a su transmisor y, siempre es transmisora de la voluntad divina y, por tanto, de la verdad. De este modo, la pretensión de conocer el futuro por medio de la adivinación pasó de los ritos habituales de las religiones paganas tradicionales a engrosar las plasmaciones de la religiosidad en los márgenes de la ortodoxia, calificándola como magia o superstición.

comunes al área de ocupación romana o colindante como es el caso de la diosa griega Afrodita, véase JBA 25 (MS 2053/280).

${ }^{3}$ La dureza del soporte estaba ligada a la capacidad adquisitiva del cliente, no de su deseo de que los productos derivados de su hechizo duraran para siempre.

${ }^{4}$ Muchos de los cuencos de magia parecen estar destinados a ser escondidos en lugares santos o guardarlos en las casas con fines protectores y salutíferos.

${ }^{5}$ En el judaísmo, atribución numérica a las letras viendo así significados ocultos en las palabras. 


\section{Los cuencos de magia.}

Este singular testimonio epigráfico próximo oriental ${ }^{6}$ ha sido datado entre los siglos IV a VIII, marcando su cierre la conquista árabe y con ella la extensión del islam ${ }^{7}$, aunque realmente su producción más activa se circunscribe a los siglos VI y VII.

El área de su praxis y la especialización de los magos o sacerdotes escribas que los confeccionaran fue Mesopotamia, aunque Persia también participó de estos ritos mágicos (ambos bajo el Imperio Sasánida al mismo tiempo $)^{8}$. Aunque también han sido encontrados en Palestina y otras zonas colindantes de Próximo Oriente pertenecientes a las mismas tradiciones socioculturales y mágicoreligiosas, evidentemente con las ligeras variantes propias de cada grupo étnico o cultual.

La elección de este material fue por ser práctico, barato y fácil de hacer ${ }^{9}$. Sus soportes redondos eran elementos ideales para escribir largos hechizos en espiral que acababan, a menudo en un dibujo abstracto $^{10}$, que solía representar una entidad demoníaca de gran originalidad y simbolismo, nunca semejante, desplegando un mar de fantasía y creatividad artesanal y atávico al mismo tiempo.

Pese a que en este estudio, al centrarse en la figura de Lilith, tan solo se abordan los cuencos de magia pertenecientes a la religión judía, otros cultos como el zoroastrismo, el cristianismo y el mandeísmo también participaron de esta forma de magia tardoantigua.

Sus textos nos muestran los miedos, angustias y deseos de los hombres y mujeres de la Antigüedad y, de cómo mediante la magia deseaban manipular y transformar su realidad, y restaurar el orden

\footnotetext{
${ }^{6}$ La amplísima colección Schøyen testimonia la importancia y popularidad que llegó a alcanzar esta forma de magia en la Antigüedad Tardía de la franja del Creciente Fértil. Sobre los cuencos de magia tardoantiguos véase también: Bohak, G. Ancient, Jewish Magic. A History, Cambridge University Press, Cambridge, 2011, pp. 65, 110, 111, 183-93, 248, 253, 268- 69, 271, 276, 278, 280, 297, 302, 309, 312, 320, 334, 337, 338, 340, 347, 391, 409; López Fernández, E. Escritos Mandeos, Biblioteca de Autores Cristianos, Madrid, 2013, 4950; Martínez Boribio, E. "A Magical Bowl in Judeo- Aramaic", Isimu: Revista sobre Oriente Próximo y Egipto en la antigüedad, ISSN 1575-3492, N. 6, 2003, pp. 323-336; Montgomery, J. A. Aramaic Incantation Texts from Nippur, Philadelphia, Published by the University Museum, 1913, pp. 37- 39, 51- 66, 244- 255; Shaked, S.; Nathan Ford, J. and Bhayro, S. Aramaic Bowl Spells. Jewish Babylonian Aramaic Bowls. Volume One. Brill, Leiden- Boston, 2013; Yamauchi, E. M. Mandaic Incantation Texts. Gorgias Press, USA, 2005 y Scotten, A. G., Magic and Inter-Communal Relations in Sasanian Iraq. The Case of the Incantations Bowls, Chicago, 2007, pp. 28- 31; Oelsner, J. "Incantations in Southern Mesopotamia-From Clay Tablets to Magical Bowls (Thoughts on the Decline of the Babylonian Culture)" pp. 31- 52 y "Tablets and Magic Bowls" Geller, M. J. 53- 72 en Shaked, Sh. (Ed.) Officina Magica. Essays on the Practice of Magic in Antiquity, Brill, Leiden, Boston, 2005; consultar además el corpus digitalizado de la Schøllen Collection https://www.schoyencollection.com

${ }^{7}$ La prohibición de la magia en los monoteísmos no hizo cesar totalmente su práctica y, con la llegada del culto mahometano esto no iba a ser distinto.

${ }^{8}$ Shaked, S.; Nathan Ford, J. and Bhayro, S. Op.cit., 2013, p. 1.

${ }^{9}$ Shaked, S.; Nathan Ford, J. and Bhayro, S. Op.cit., 2013, p. 2.

10 Sobre las pinturas y representaciones demoníacas, tanto de formas humanas como animalescas, véase: Naama Vilozny, "The Art of the Aramaic Incantation Bowls", en Shaked, S.; Nathan Ford, J. and Bhayro, S. Op. cit., 2013, p. 29- 39.
} 
de las cosas malogradas, ya fuera por la enfermedad, los problemas psicosexuales ${ }^{11}$, o las fuerzas espirituales maléficas y oscuras que por alguna razón les perturbaban.

Según Shaud Shaked:

We may reasonably assume that the practice of writing texts on bowls could be described as a way of appealing to the higer powers, such as God and his angels, for help with pressing human needs, mainly health problems and sexual fears, both attribued largely to demons. Put in these terms, the production of these magic texts could arguably be regarded as an exercise in piety $^{12}$.

El contenido va más allá de los contextos psicológicos, sociales o históricos que podamos percibir a través de estas manifestaciones religiosas heterodoxas, pues los cuencos de magia judeo- aramaicos entran en conexión con tradiciones textuales dispares como la de los Rollos del Mar Muerto, los textos más tempranos de la Hekhalot o textos místicos judíos, de la oración Shema, o extractos de la Mishná ${ }^{13}$, e incluso en las fórmulas mágicas encontradas en la Genizá del Cairo ${ }^{14}$.

\section{La demonología de los cuencos de magia judeo- aramaicos.}

La abundante y diversa angeología y demonología judaica dio lugar a una personificación y especialización de estas entidades de forma singular y sin parangón. Ni siquiera el cristianismo, heredero directo del judaísmo, llegó a aceptar en la tardoantigüedad tal creencia y estudio de los seres subalternos de Dios.

La angeología y demonología judaica parece ser, en ocasiones, una trasformación de dioses paganos, reconociendo así su existencia, pero no su naturaleza divina.

Incluso es posible ver casos de ambivalencia donde la naturaleza demoníaca, reconocida por las tradiciones judeocristianas como tal sin duda alguna, pasan a ser angélicas. Tal es el caso de Asmodeo $^{15}$, pareja tradicional de Lilith y padre de sus vástagos.

\footnotetext{
${ }^{11}$ La parte concerniente a los escritos mágicos de divorcios como exorcismos, nacida de un intimismo de tradición religiosa mesopotámica de unión a dioses paganos regionales de componente erótico y amoroso, es decir, sexual y filial (hierogamia), puede que produjera, por asimilación, desordenes sexuales y confusión en los judíos de la diáspora residentes en Próximo Oriente, al mezclar cultos paganos extranjeros con los propios, dando origen por otra parte a una rica tradición demonológica, como problema trascendente y unas fórmulas y amuletos profilácticos o apotropaicos (cuencos y otros objetos) como solución mágica.

${ }^{12}$ Shaked, S.; Nathan Ford, J. and Bhayro, S. Op.cit., 2013, pp. 7- 8.

${ }^{13}$ Shaked, S.; Nathan Ford, J. and Bhayro, S. Op.cit., 2013, p.1. Ver también Marcos Casquero, M. A. Lilith. Evolución histórica de un arquetipo femenino, Universidad de León, León, 2009, pp. 18- 19.

${ }^{14}$ Shaked, S.; Nathan Ford, J. and Bhayro, S. Op.cit., 2013, p. 2.

${ }^{15}$ En uno de los escritos de divorcio/ exorcismos el hechicero jura por el nombre del ángel Ashmedai. JBA 58 (MS 2053/166).
} 
Entre las potencias angélicas presentes en los textos mágicos de los cuencos de magia judeoaramaicos se encuentran los tres arcángeles principales (Miguel, Gabriel y Rafael) y Nurael, así como otros de marcada relevancia por su poder y cercanía a Dios como Metatrón y; entre las entidades demoníacas Lilith (Halbat y Zanay), Elisur Bagdana ${ }^{16}$ rey de los demonios y dēvs ${ }^{17}$ y gran gobernador de liliths, Quitaros y su poderosa lanza ${ }^{18}$, etc.

Las variadas denominaciones a los cuantiosos demonios y espíritus inmundos inferiores reflejan los terrores y el mundo psicológico y la realidad alterada de los judíos solicitantes o clientes de estos hechizos, en la necesidad de calmar las anomalías surgidas en sus vidas, pues los demonios son, en las creencias tardoantigüas comunes a todas las religiones, los causantes últimos de sus males, los responsables de sus enfermedades tanto físicas como psicológicas, así como los perturbadores espirituales de sus hogares y, lógicamente, la erradicación de su presencia es la única forma de mitigar, calmar y restaurar el orden natural de las cosas y recurrir al divorcio/ exorcismo es el procedimiento para volver a recuperar la salud y la armonía ontológica.

\section{Lilith en la mitología y literatura antigua hebrea.}

De orígenes ancestrales, tenemos constancia de ella, como espíritu o demonio de la noche, ya sea masculino o femenino en los albores de la literatura sumeria, en la propia epopeya de Gilgamesh ${ }^{19}$, denominados lilu y lilitu respectivamente. Sabemos que su nombre hebreo (לילית lîlit) es un préstamo del acadio (lilitu) y este, a su vez, del sumerio (lîl). Estos demonios eran asociados primitivamente a los vientos tormentosos, por lo que la palabra lilû puede ser interpretado como viento del sureste, por lo que se cree que ella puede entrar por la ventana volando como lo haría un pájaro $^{20}$. Su tímida presencia en la Biblia se hará a través de los textos proféticos, en concreto en Isaías $34: 14^{21} \mathrm{y}$, se la asociará a otras bestias ${ }^{22}$ o demonios. En el Talmud ella es un demonio con el

\footnotetext{
${ }^{16}$ Este demonio, al igual que Lilith Zanay, la chica cantante fornicadora, también tiene su propia tradición mágica en los cuencos de magia judeo- aramaicos, de hecho más amplia que la de la Lilith citada. JBA 27 (MS 1927/ 16); JBA 28 (MS 1927/ 25); JBA 29 (MS 1927/ 51); JBA 30 (MS 1928/ 47); JBA 31 (MS 2053/41); JBA 32 (MS 2053/64); JBA 33 (MS 2053/83); JBA 34 (MS 2053/86); JBA 35 (MS 2053/89); JBA 36 (MS 2053/110); JBA 37 (MS 2053/123); JBA 38 (MS 2053/151); JBA 39 (MS 2053/162), JBA 40 (MS 2053/167); JBA 41 (MS 2053/184); JBA 42 (MS 2053/190); JBA 43 (MS 2053/193); JBA 44 (MS 2053/213); JBA 45 (MS 2053/237); JBA 46 (MS 2053/249); JBA 47 (MS 2053/258); JBA 48 (MS 2053/200).
}

${ }^{17}$ De etimología protoindoeuropea alusiva a su condición de ser celestial o brillante, esta denominación (dēvs o devas) será usada para los dioses benévolos del hinduismo y del budismo.

${ }^{18}$ Demonio heredero de la tradición de los Smiting gods surgidos en la Edad del Broce y de tradición iconográfica oriental (Egipto y Canaán) y presentes a lo largo de la costa mediterránea (las tendencias sincréticas darían lugar a la representación de los dioses patrios griegos en actitud punitiva como Zeus o Poseidón) por la difusión de las ideas y creencias religiosas, el arte y la estética orientalizante con la colonización (fenicia y cartaginesa) y el mercado naval.

${ }^{19}$ Marcos Casquero, M. A. Op. cit., 2009, pp. 63- 67.

${ }^{20}$ Dictionary of Deities and Demons in the Bible, (edit. Karel van der Toorn; Bob Becking; Pieter W. van der Horst), Brill, Leiden, 1999, p. 520.

${ }^{21}$ Jerónimo tradujo su nombre en la Vulgata como Lamia. Sobre la breve alusión de Isaías a esta criatura véase Marcos Casquero, M. A. Op.cit., 2009, pp. 35- 62. 
pelo largo y alas, que seduce y ataca a los hombres en la noche, de ahí que los rabinos les adviertan y prevengan ${ }^{23}$, siendo coincidente con la descripción que sustenta los cuencos de magia judeoaramaicos.

Este personaje mitológico maligno trascendió y permeabilizó en todas las religiones de Oriente, desde los mesopotámicos paganos, a los zoroastristas, judeocristianos, incluyendo a las sectas más apartadas y controversiales como los mandeos, pululando cual ave nocturna entre los miedos y pesadillas de hombres y mujeres de Oriente, así como los de Occidente, debido al traspase cultural y religioso fruto de las zonas fronterizas o limítrofes, las corrientes migratorias, las colonizaciones, y las rutas mercantiles, todas ellas transmisoras de ideas y riqueza sociocultural.

Etimológicamente, el nombre de Lilith לילית, que designa a un demonio femenino o espectro nocturno, está ligado a la lechuza o al búho. Su raíz de la cual proviene la nomenclatura que designa a esta realidad es la de la palabra $\left\langle<\right.$ noche $>>{ }^{24},\langle\langle$ oscuridad $>>$, o $<\langle$ penumbra $>>$, לילה que en un sentido figurativo puede significar $\langle<$ calamidad $\rangle\rangle$ o $\langle<$ desgracia $\rangle\rangle$, de donde también $<<$ nocturno >>, <<oscuro >>, <<tenebroso >> o <<sombrío >> ליל ${ }^{25}$, e incluso su derivación $<<$ pasar la noche $>>0<<$ hacer pasar la noche $>>{ }^{26}$, en un sentido más ambiguo, oscilando entre el terror de las tinieblas ancestral al erotismo y sensualidad asociados a la nocturnidad.

Para la mitología y tradición hebrea posterior Lilith, que pertenece al grupo de los mazikim ${ }^{27}$ o <<espíritus dañosos o perjudiciales〉>, nació en un mito sexual como primera esposa y compañera de Adán, pero al contrario de como se originó el primer hombre y compañero diseñado y moldeado del barro cual vasija que habría de contener un espíritu o soplo divino, o Eva, formada por Dios de la costilla del primer hombre, de la parte más cercana al corazón de su compañero, con una simbología llena de amor y dignidad, Lilith fue formada por Dios del estiércol y la grava ${ }^{28}$, con una

${ }^{22}$ Entre ellos, hienas, búhos leonados, buitres. Dictionary of Deities and Demons in the Bible, Op. cit., 1999, p. 521. Animales salvajes, carroñeros y rapaces, asociados al rapto, la carne, la sangre y la muerte.

${ }^{23}$ Erub. 100b; Nd. 24b. Dictionary of Deities and Demons in the Bible, Op.cit., 1999, p. 521. Marcos Casquero, M. A. Op.cit., 2009, pp. 85- 93.

$24<<$ Lilitu, Lilith, and the Lamias are nigth creatures, and the world of the dead is dark from Egipt to Greece and Iran to Rome>>, Burton Russell, J. The Devil. Percepetions of Evil from Antiquity to Primitive Christianity, Cornell University Press, 1987, p. 253.

${ }^{25}$ Recuérdese que una de las formas de nombrar a este demonio o su raza en ocasiones no lleva la $\Omega$ final propia de las terminaciones femeninas, por lo que su pronunciación es muy parecida.

${ }^{26}$ Targarona Borrás, J. Diccionario Hebreo/ Español, Riopiedras, Barcelona, 1995. Según Marcus Jastrow este demonio también alude metafóricamente al sufrimiento o la miseria. Jastrow, M. A Dictionary of the Targumim, the Talmud Babli and Yerushalmi, and the Midrashic Literature. https://en.wikisource.org/.../A_Dictionary_of_the_Targumim (10/04/19).

27 Estos espíritus malignos desempeñan varios roles, especializándose en distintas calamidades. http://www.jewishvirtuallibrary.org/lilith (28/03/ 2018).

${ }^{28}$ Inmundicia y sedimentos según otras versiones, Graves, R y Patai, R. Los Mitos Hebreos, (traducción de José Luis Gil Aristu), Gredos, Madrid, 2012, p.77. 
carga simbólica potente: sucia, degenerada y pútrida, muestra un ser con una esencia repugnante, ruda, insensible, abyecta, vil, despreciable y predispuesta hacia el mal.

El mito gira en torno al sexo y la libertad de ella, como primera fémina, que no mujer. Su origen determinista parece ser exclusivamente el ser la compañera sexual de Adán ${ }^{29}$, pero la negativa de Lilith a someterse a la voluntad, posesión o dominación sexual de Adán al quedar posicionada en el coito bajo su compañero varón, da un matiz humillante a la sexualidad y a la relación entre ambos, tema que se presta obviamente a interpretaciones freudianas del mito. Por lo que huyendo del primer hombre para la que había sido creada, pidió ayuda a Dios y éste le concedió alas y voló hasta el mar Rojo donde se unió a un ser más afín ella, en cuanto a naturaleza, Sammael ${ }^{30}$, Satanás ${ }^{31}$ o Asmodeo $^{32}$, dependiendo de la versión ${ }^{33}$, con los que engendró demonios, que en la Edad Media se los llamaría súcubos e íncubos ${ }^{34}$, vinculados al sexo, a la noche y al sueño.

La razón de ser o determinismo o fatalismo natural o social, el sometimiento a la autoridad patriarcal (padre -como sometedor y rescatador a partes iguales sin contradecirse en sus decisioneso marido -autoritario y posesivo cuyo papel o rol social y familiar se reduce a lo meramente sexual), la libertad, la rebeldía, parecen ser algunos de los debates socioculturales que subyacen de este mito; pero la diversidad de versiones hace cuestionarse si esta última no fue una relectura de un mito más oscuro y acorde con la época, pues otras leyendas hablan de que llegó a ser consorte de Dios, quizá para cubrir o tapar el culto ancestral a Asera o Asherah, diosa asociada un tiempo a Yahvé como su consorte en tiempos bíblicos con otros nombres y relatos que, en cierto modo,

${ }^{29}$ Aunque el inicio lúdico o jocoso del mito en principio no parece nada edificante, su desarrollo, que no su final, girará en torno a valores más positivos y que inspiran a la reflexión sobre la libertad.

${ }^{30}$ Arcángel de la muerte cuyo nombre es traducido por $<<$ Veneno de Dios $>>$ o $<<$ Ceguera de Dios $\rangle>$.

${ }^{31}$ Demonio bíblico por antonomasia, tanto del Antiguo como del Nuevo Testamento, su nombre significa <<el Adversario>>, el judeocristianismo temerá a este demonio secularmente, ya que su nombre llegó a ser sinónimo de demonio por excelencia o sintetización de otras o todas las personalidades demoníacas al denominarle como <<el Demonio>>, al que se creía que Dios le concedió un gran poder al ser llamado <<el Príncipe de este Mundo $>$.

${ }^{32}$ Antagonista demoníaco del Libro de Tobit o Libro de Tobías, sus orígenes se remontan al zoroastrismo y su nombre está presente en el Talmud.

${ }^{33} \mathrm{Su}$ personaje y mito, con múltiples versiones orales que dieron como resultado cierta confusión, son resumidos así: <<Lilit es un demonio femenino de la noche, tiene alas, se alimenta de hombres, pone en peligro a las parturientas y estrangula a los recién nacidos. Parece que procede de la antigua demonología babilónica y de una clase de espíritus femeninos malignos llamados lilitu. La tradición judaica cuenta que cuando Adán y Eva se separaron, él engendró demonios con los espíritus que se unieron a él. En ese momento, Lilit concibió con él muchos demonios masculinos y femeninos. El relato más conocido es el que cuenta que Lilit fue la primera esposa de Adán, creada antes que Eva. Lilit se negó a someterse a él y, pronunciando el nombre de Dios, se alejó volando. Más adelante se convirtió en la primera pareja de Sammael. Otra narración explica que durante un tiempo fue consorte de Dios > . VV. AA. Mitología. Todos los mitos y leyendas del mundo, Barcelona, 2005, p. 335. Véase también: Dictionary of Deities and Demons in the Bible, Op.cit.1999, p. 521.

\footnotetext{
${ }^{34}$ Originalmente llamados lilim Graves, R y Patai, R. Op. cit., 2012, pp. 78 y 81.
} 
rememorasen este hecho en tiempos donde la tendencia teológica judaica imperante era el farisaísmo rabínico.

Por tanto, es posible concluir que en la literatura liliana antigua no parece haber rastro del pavor, estremecimiento y terror que infundía, inspiraba o transmitía Lilith que se revelan a través de los textos conservados en la epigrafía de los cuencos de magia judeo- aramaicos, más cercanos a las creencias y miedos de las personas y comunidades religiosas que generaron estos documentos e, igualmente de datación más temprana y original o primigenia que el mito reelaborado en su plasmación escrita; pero sí que ya está presente desde el principio su nocturnidad, su acecho cual ave rapaz o de presa (adopta la forma de un búho o lechuza), sus orígenes inmundos y antihumanos, su perversidad, su libertad entendida como libertinaje en el mundo antiguo, y su lujuria.

\section{La Lilith de los hechizos judeo- aramaicos.}

La compleja y extensa demonología judaica presente en los cuencos de magia nos ofrece una visión y especialización de la persona demoníaca de Lilith muy distinta de la observada en los textos literarios y mitología de tradición oral conservada de ella.

El nombre de Lilith es prácticamente omnipresente en los escritos de magia de los cuencos judeoaramaicos.

Si bien es cierto que es a Rabbí Ḥanina Ben Dosa al primero que se le adjudica este tipo de tradición exorcística dentro del judaísmo rabínico, él exorcizó a un espíritu maligno inidentificado, que más tarde sería asociado a la demonesa Agrat, del que tomaron esa historiola para dar fuerza y justificación a un modelo específico de hechizo y exorcismo ${ }^{35}$; es a Rabbí Joshua bar Perahia a quien se le adjudica tanto el haber diseñado o adaptado el modelo de divorcio judaico ${ }^{36}$ como exorcismo para expulsar a los demonios de las personas y hogares, con una connotación muy intimista de la posesión y las casas encantadas, reconociéndolas implícitamente como una relación matrimonial $^{37}$, casi con un componente voluntario, como si las víctimas de enfermedades, demonios

\footnotetext{
$35<<$ The motif of Hannina ben Dosa that recurs in the bowls deals with his encounter with a female demon, identified simply as rwh' byšt' "an evil spirit". He recites a biblical verse against her (Ps 104: 20) and thereby vanishes her. This is a historiola that introduces an exorcism of various spirits and demons as part of the encantations >>. Shaked, S.; Nathan Ford, J. and Bhayro, S. Op.cit., 2013, p. 53.

${ }^{36}<<$ The demonic attachment is compared metaphorically and half- seriously to the permanence of marital relations (perhaps with a hint in the direction of a possible sexual connection with demons). Given these premises, the most effective way to end this relationship is to establish a legal separation. (...) The divorce formula would simultaneusly achieve two conflicting aims: it would legitimise the demon by retroactively recognising its quasi- married status, and at the same time outlaw it by annuling that status. This is the essence of divorce trick. (...) The divorce theme underlines the ambiguity of the demonic presence in human society. The demons are beyond humans reach and ken, and yet they form a kind of invisible part of society>>. Shaked, S.; Nathan Ford, J. and Bhayro, S. Op.cit., 2013, p. 99.

${ }^{37}$ La posibilidad de la unión íntima (amorosa y sexual) entre un humano y un demonio parece ser un recuerdo remoto de la hierogamia de la antigua tradición mesopotámica, fenómeno místico- ritual en el que un mortal podía unirse a un ser divino en un enlace trascendente e inmanente, al mismo tiempo, espiritual y físico a la vez. Noah Kramer, S. El Matrimonio Sagrado en la Antigua Súmer, (traducción y adaptación de Manuel Molina). Editorial AUSA Sabadell, 1999.
} 
y malos espíritus e infestaciones hubieran buscado de alguna forma su mal y estuviesen padeciendo o sufriendo los efectos preternaturales de la culpa por sus pecados en sus formas más aterradoras; tanto como de haber sido quien maldijo a Lilith.

En primer lugar es necesario hablar de su multiplicidad y tipología ${ }^{38}$, pues los cuencos nos hablan de una multitud de ellas, a veces despersonalizadas, otras individualizadas, y en algunas ocasiones muy concretas, con apellidos y genealogías.

También hemos de distinguir su sexo, pues los hechizos de los cuencos de magia rompen con la literatura y mitología creando una tipología de las mismas, liliths masculinos y liliths femeninos ${ }^{39}$, que derivarán de forma vehicular, pese a que tan solo hay un documento claro que atestigüe ese proceso, de los liliths como linaje a los íncubos y súcubos medievales, como podemos apreciar de forma clara en el cuenco de magia encargado por Gisa hija de Ifra- Hormis ${ }^{40}$. En este hechizo ya podemos ver cómo Lilith engendró demonios ${ }^{41}$ y estos seres infames y perversos adquieren una connotación sexual excesivamente íntima, sustituyendo como avatares invertidos a la pareja real.

Entre las formas definidas y caracterizadas de Lilith hemos de especificar que ella es descrita como una mujer desnuda, que no tiene ropa alguna, de pelo largo y alborotado que le cae por la espalda. Es ladrona o raptora ${ }^{42}$. Su familia es descrita puntualmente (para despojarla de secretos, para poder vencerla y someterla al hechizo, exorcismo o divorcio) su padre es Palhas y su madre lilith Palhadad $^{43}$. Existe una amplia tradición de cuencos que específicamente quieren exorcizar/ divorciarse de Lilith Zanay ${ }^{44}{ }^{45}$, la chica cantante fornicadora ${ }^{46}$, a la que llaman la maldita, un ser

\footnotetext{
${ }^{38}$ En ocasiones se referirán a ellas, indistintamente, incluso en el mismo hechizo, como liliths o lilis.

${ }^{39}$ Por ese orden serán citados en los textos, rompiendo con la tradicional visión del espíritu demoníaco femenino y creando una estirpe o raza.

${ }^{40}$ JBA 64 (MS 2053/256).

${ }^{41}$ Parece que este conjuro/ divorcio responde más al mito de Lilith como madre de demonios, de tal forma que, ya podríamos afirmar que el mito de Lilith como primera esposa de Adán y engendradora de demonios, llamados íncubos y súcubos con posterioridad, ya estaba configurado en sus líneas esenciales. Ana María Vázquez Hoys nos recuerda que Lilith, según el Talmud y los escritos rabínicos, no es solo madre de demonios sino también de gigantes. Vázquez Hoys A. M. Arcana Magica. Diccionario de símbolos y términos mágicos, UNED Ediciones, Madrid, 2003, p. 331.
}

${ }^{42}$ Quizá de cosas perdidas de la casa como un moderno poltergeist, quizá de niños por ser el lado tenebroso femenino y, por tanto antimaterno. Su aversión a los niños se manifiesta en su naturaleza ponzoñosa, pues se dice que da el pecho a los niños cual nodriza, pero en vez de leche hay veneno en sus senos. Dictionary of Deities and Demons in the Bible, (edit. Karel van der Toorn; Bob Becking; Pieter W. van der Horst), Brill, Leiden, 1999, p. 520. En un contexto tardío puede que estas palabras tuviesen un sentido de seductora en cuanto a entrometerse en las relaciones sexuales conyugales humanas (pues el divorcio/ exorcismo da por hecho que también existe este tipo de unión marital entre demonios y mixtas, es decir, entre seres humanos y criaturas demoníacas).

${ }^{43}$ Existe una extensa familia de liliths (masculinos y femeninos) y la tradicional no es la primera ni la última.

${ }^{44}$ Véase los cuencos de magia JBA 50 (MS 2053/ 207); JBA 51 (MS 2053/209); JBA 52 (2053/ 231); JBA 53 (MS 2053/253); JBA 54 (MS 2053/273), todas ellas parece que fueron solicitadas por la misma persona Immi hija de Qaqay. 
agresivo increíblemente violento que masacraba en matanzas a sus propios hijos y a los de sus compañeras $^{47}$; asociada a otros demonios, a las artes mágicas y a las imprecaciones y otros demonios, que parecen ser femeninos e igualmente singularizados como Danahis y Romi, un ser por tanto muy peligroso y cuya presencia suscitaba la angustia y desesperanza a quien necesitaba los servicios del conjurador y escriba del texto, pues dicho demonio femenino había atraído la desgracia a la casa, posiblemente materializada con la muerte de un hijo o niño ${ }^{48}$ en el domicilio.

${ }^{45}$ En la tradición de textos del ser demoníaco Elisur Bagdana, entre otras, Lilith Hablas es identificada como la nieta de Lilith Zarnay o Zanay.

${ }^{46}$ El oficio de las cantantes en la Antigüedad y, específicamente en este marco cronológico tardoantiguo y próximo oriental en que se centra este estudio, parece estar relacionado con la promiscuidad sexual que, al menos se les asignaba. Recuérdese la conspiración de Herodías y de cómo utilizó a su hija Salomé para obtener, por medio de su baile sensual, la cabeza de Juan el Bautista (Mt 14:1-12, Mc 6:14-29 y Lc 9:7-9). La diosa de Uruk, Inanna, es descrita como <<la doncella que siempre chilla $>>$ y como <<alegría de cada corazón〉>. Marcos Casquero, M. A. Op.cit., 2009, pp. 35- 62. Como icono erótico- sincrético Lilith es asociada a la diosa pagana helena Afrodita, de quien se dice que todos son esclavizados. JBA 25 (MS 2053/280).

${ }^{47}$ En ocasiones los textos parecen referirse a los propios y a los hijos de las compañeras demonesas y otras veces a las mortales víctimas de los caprichos de su aterradora naturaleza perversa. Por entrometerse en el sexo de los recién casados, los matrimonios consolidados y el parto de los mortales se la teme: <<Lamias roamed the world seeking the death of children and sexual intercourse with sleeping men, much like the Hebrew Lilith >>, <<The Lamias easily merged with Semitic Lilith to create the image of the lewd and murderous female spirit who ventures out at nigth seducing men and killing infants, an image that the Middle Ages gradually shifted from the supernatural to the natural realm, fixing it finally upon the witch $>>,<<$ Lilith and her followers roamed the world seducing men and attacking children with murderous intent, and other she- demons went about at nigth strangling sleeping men〉> Burton Russell, J. Op.cit., 1987, pp.143, 172 y 215 , respectivamente; <<Until this, purification, being unclean, he and his bride are peculiary susceptible to the attacks of demons and liliths>> E. S. Drower, The Mandaeans of Iraq and Iran. Their Cults, Customs, Magic Legends, and Folklore, Oxford at Clarendon Press, Great Britain, 1937, p. 65; <<era muy temida por las mujeres judías en el momento del parto y las comadronas judías hacían escribir (y aún hoy lo hacen) en las paredes de la habitación en que se iba a desarrollar el parto una fórmula mágica para detenerla y ahuyentarla: ADIM CH ANAH CHUTS LILITH, o sea: "que Lilith se aleje de aquí" >>. Vázquez Hoys A. M. Op. cit., Madrid, 2003, p. 330.

${ }^{48}$ Curiosa y contradictoriamente, los mandeos, que creen en la existencia de los liliths como espíritus femeninos malignos que asesinan a los niños, tienen una variante positiva para estos seres, otorgándoles bondad y protección a la maternidad y cuidado del bebé antes y después de nacer, siguiendo en cierto modo una tradición pagana de seres sobrenaturales, de mayor y menor rango, custodios y veladores de la maternidad y la infancia $<<$ There is a special genius concerned with chilbirth who is responsible for well- being of the infant before it is born and after. In the Drasha $\underline{d}$ Yahya she is spoken of as lilith, bute ven there, the term is not used opprobiusly, and in general, she is looked upon as kindly spirit of ligth. Her name is Zahari il and she seems to be related to Ishtar or Venus (Zahara) in the capacity of genious of generation and childbirth. Shaikh Dukhayil identified her with the latter also with Simit Hiia. In myth, she is the wife of Hibil Ziwa, who espoused her in the realms of darkness>>. E. S. Drower, The Mandaeans of Iraq and Iran. Their Cults, Customs, Magic Legends, and Folklore, Oxford at Clarendon Press, Great Britain, 1937, pp. 46- 47; <<The birth of John, (...), was the result of a trick by Lilith, a female demon who assist women in labor an who helped Elizabeth. The Jews, in fact, had leaned through dreams of John's imminent birth, had decided to kill him, and had involved all midwives in the plan. Lilith, however, was able to decive them all, having the baby born in an unexpected way and entrusting him immediately to Anuš 'Utra, who took him off to a distance, blessed mountain where the boy could grow up in peace〉>. Lupieri, E. The Mandaeans. The Last Gnostics, 
El objetivo del divorcio/ exorcismo es la separación material y espiritual de Lilith, provocar su retirada y no regreso, alejarla lo máximo posible del alma y cuerpo, de la familia (de los hijos habidos y por haber) y del hogar, núcleo íntimo y sagrado extensivo a las personas que lo habitan, y cuya profanación o intrusión altera y desordena el microcosmos del espacio vital y espiritual necesarios para la salud física y mental de los moradores; por lo que los hechizos de los cuencos verbalizarán, entre otras fórmulas, el ataque hacia Lilith como entidad demoníaca con la expresión y deseo de golpearla en su pericardio, o en otras palabras de dañar o herir su corazón, tal vez como la expresión de la ruptura amorosa que implica el divorcio (en Lilith aparece inherente desde prácticamente sus orígenes como demonio individualizado y personalizado el contenido erótico), o como manifestación del deseo de rencor, odio y venganza por los males y desgracias ocasionados, pues el corazón no solo es el órgano que simbólicamente es la sede del amor y el deseo, sino también, la mente, la inteligencia, la razón y la vida, más allá de la simbología antigua, por eso golpearlo es desearle un gran daño, dolor y sufrimiento, aunque lo que de verdad trasciende a estas palabras es un deseo de muerte, aunque tanto el cliente/s como el escriba y conjurador son conscientes de la imposibilidad de atacar así a un ser inmortal.

Así Lilith, y su raza, se muestran como seres agresivos, perturbadores, intimidantes, acosadores, hostigadores, amenazantes, extremadamente agresivos y sádicos, especialmente con los hijos e hijas de la familia, o compañeras amigas de la familia, donde hospedaran como intrusos (tal vez huéspedes si fueron invocados) y parásitos, habitualmente ocupando el umbral ${ }^{49}$ de la casa, cual ave rapaz $^{50}$, donde poder hostigar mejor a su presas, relacionadas quizá con la irrupción de la maternidad, tal vez el aborto o la mortandad infantil, por la naturaleza femenina y cruel de este demonio o espíritu maligno, pero también con una connotación de seres sexuales muy definidos y salvajes, primitivos pero eróticos que componían una estructura de mujer enloquecida, indómita, asilvestrada y seductora que irrumpía con el orden y los tabúes sexuales religiosos especialmente aplicados a las mujeres judías acercándola al mito liliano medieval.

\section{Conclusiones.}

Los hechizos, encantamientos, exorcismos y divorcios presentes en los textos epigráficos de los cuencos de magia judeo - aramaicos presentan la esencia de la demonología judaica de la antigüedad tardía en su más puro estado, sin interpolaciones o censuras literarias inoportunas que

(translated by Charles Hindley), William B. Eerdmans Publishing Company, Grand Rapids, Michigan/ Cambridge U. K., 2002, pp. 120- 121.

${ }^{49}$ El umbral o límite de una casa u otra construcción o lugar natural es un paso o frontera mágico entre dos mundos, un cambio iniciático entre ambas realidades, conformando el propio sendero que sirve de nexo entre ambas como una realidad propia dotada de poderes, fuerzas y criaturas mágicas que sirven de prueba transicional de aquel que se atreve a cruzarlo. Por ello los umbrales, límites y puertas eran protegidos con oraciones, hechizos y amuletos diferentes $<<$ The threshold is of importance, and is protected by charms $>$ (p. 50) dijo E. S. Drower. Entre los casos de la superstición romana relacionada con el umbral encontramos la offensio pedis, y en el mandeísmo varios ritos de sacrificios animales practicados por los laicos pero calificados por los sacerdotes como <<irreligiosos〉>, por citar algunos ejemplos entre las religiones antiguas, cuya finalidad era proteger el hogar u otra edificación de las fuerzas del mal $<<$ to prevent evil influences or disease demons from passing in > E. S. Drower, Op. cit., 1937, p. 50.

${ }^{50}$ Hay que recordar que Lilith es simbolizada como un búho o lechuza, un ave rapaz de nocturnidad y astucia que arrebata y atrapa a sus víctimas entre tinieblas. 
entorpezcan la labor del estudioso de las religiones y creencias, elitistas y populares, pretéritas; y en concreto sobre la naturaleza y persona de Lilith, objeto y sujeto del presente estudio, si bien muy diferente a la de la literatura y mito hebraico, e incluso judeocristiano, medievales, son confluyentes $\mathrm{y}$ transicionales a los mismos.

Hemos de ver la figura Lilith como el resultado sincrético final de la concepción de la diosa del amor y la guerra próximo- oriental, conservando su carácter erótico y salvaje, amoroso y violento de las diosas orientales, aunque en los cuencos de magia judeo- aramaicos ya se presenta algo domesticada, adaptada a un judaísmo rabínico heredero de las tradiciones mesopotámicas desde tiempos del cautiverio babilónico que fue asumiendo poco a poco, filtrándose en su religión monoteísta perseguida en tierras extranjeras, la existencia de seres sobrenaturales ajenos a la divinidad, ídolos, en este caso femeninos que pasaron a ser en su cosmovisión de dioses a demonios perturbadores de su realidad y que atentaban contra su salud física y mental.

Aunque, tanto singularizada en las personas de su genealogía como pluralizada en su estirpe o raza, ella es, como demonio y fémina, una representación simbólica de la antifeminidad para la ideología rabínica tardoantigua y medieval, según el criterio de estos sabios y maestros guardianes de su fe en lo referente a la concepción antropológica y sociológica concerniente a la mujer judía.

Lilith fue la asunción de las diosas mesopotámicas y cananeas antiguas Ishtar, Lamashtu, Inanna, Astraté, Asera o Astarot, así como sus herederas mediterráneas Hécate o Afrodita bajo un nombre y, por ende, nueva esencia y características de una misma realidad arcana.

Es posible afirmar que lejos de las añadiduras ideológicas distorsionadoras posteriores, propias de la literatura antigua y medieval, pretendiendo fabricar otro icono rebelde y liberador de la mujer respecto al patriarcado o los roles sociales preestablecidos a su sexo, que correspondería a la literatura más tardía y reinterpretada bajo múltiples perspectivas al margen de este estudio dando lugar a la antítesis de la feminidad clásica a otra alternativa en la imagen de la primera esposa del primer hombre; las narraciones exorcísticas sostenidas en la epigrafía presente en los cuencos de magia judeo- aramaicos nos revelan la creencia en la figura demoníaca de Lilith en su estado más primitivo, más arcaico, más atávico y, por tanto, más real y cercana a la realidad en que fueron percibidas y suscitaran la necesidad de crear estos documentos, mostrando a este demonio femenino en su más pura esencia.

\section{Bibliografía.}

-Biblia de Jerusalén, Desclée de Brouwer, Bilbao, 2009.

-Bohak, G. Ancient, Jewish Magic. A History, Cambridge University Press, Cambridge, 2011.

-Burguillos Capel. M. “Non Serviam: La Insubordinación Femenina en el Mito de Lilith”, en Locas, escritoras y personajes femeninos cuestionando las normas: XII Congreso Internacional del Grupo de Investigación Escritoras y Escrituras (Ponencia) Sevilla, 2015, pp. 188- 198.

-Burton Russell, J. The Devil. Percepetions of Evil from Antiquity to Primitive Christianity, Cornell University Press, 1987. 
-Dictionary of Deities and Demons in the Bible, (edit. Karel van der Toorn; Bob Becking; Pieter W. van der Horst), Brill, Leiden, 1999.

-E. S. Drower, The Mandaeans of Iraq and Iran. Their Cults, Customs, Magic Legends, and Folklore, Oxford at Clarendon Press, Great Britain, 1937.

-Geller, M. J. "Tablets and Magic Bowls" 53- 72; en Shaked, Sh. (Ed.) Officina Magica. Essays on the Practice of Magic in Antiquity, Brill, Leiden, Boston, 2005.

-Gilgamesh, (Versión de Stephen Mitchell), Alianza Editorial, Madrid, 2008.

-Graves, R y Patai, R. Los Mitos Hebreos, (traducción de José Luis Gil Aristu), Gredos, Madrid, 2012.

-López Fernández, E. Escritos Mandeos, Biblioteca de Autores Cristianos, Madrid, 2013.

-Lupieri, E. The Mandaeans. The Last Gnostics, (translated by Charles Hindley), William B. Eerdmans Publishing Company, Grand Rapids, Michigan/ Cambridge U. K., 2002.

-Marcos Casquero, M. A. Lilith. Evolución histórica de un arquetipo femenino, Universidad de León, León, 2009.

-Martínez Boribio, E. "A Magical Bowl in Judeo- Aramaic", Isimu: Revista sobre Oriente Próximo y Egipto en la antigüedad, ISSN 1575-3492, №. 6, 2003, pp. 323-336.

-Mendoza Forrest, Witches, Whores and Sorceres. The Conception of Evil in Early Iran, University of Texas Press, Texas, 2012.

-Montgomery, J. A. Aramaic Incantation Texts from Nippur, Philadelphia, Published by the University Museum, 1913.

-Noah Kramer, S. El Matrimonio Sagrado en la Antigua Súmer, (traducción y adaptación de Manuel Molina). Editorial AUSA Sabadell, 1999.

-Oelsner, J. "Incantations in Southern Mesopotamia-From Clay Tablets to Magical Bowls (Thoughts on the Decline of the Babylonian Culture)" pp. 31- 52; en Shaked, Sh. (Ed.) Officina Magica. Essays on the Practice of Magic in Antiquity, Brill, Leiden, Boston, 2005.

-Shaked, S.; Nathan Ford, J. and Bhayro, S. Aramaic Bowl Spells. Jewish Babylonian Aramaic Bowls. Volume One. Brill, Leiden- Boston, 2013.

-Targarona Borrás, J. Diccionario Hebreo/ Español, Riopiedras, Barcelona, 1995.

-Yamauchi, E. M. Mandaic Incantation Texts. Gorgias Press, USA, 2005.

-Scotten, A. G., Magic and Inter-Communal Relations in Sasanian Iraq. The Case of the Incantations Bowls, Chicago, 2007.

-Vázquez Hoys A. M. Arcana Magica. Diccionario de símbolos y términos mágicos, UNED Ediciones, Madrid, 2003. 
-VV. AA. Mitología. Todos los mitos y leyendas del mundo, RBA, Barcelona, 2005.

\section{Webs.}

-https://en.wikisource.org/.../A_Dictionary_of_the_Targumim(10/04/19).

-https://www.schoyencollection.com

-http://www.jewishvirtuallibrary.org/lilith (28/03/ 2018). 